\title{
PKM Pemberdayaan Guru SLB Khusus Autis Permata Hati Dan SLB YPAC Manado Melalui Pelatihan Produksi Minuman Kesehatan Granul Instan Jahe Merah (Zingiber Officinale) Sebagai Upaya Peningkatan Kemandirian Ekonomi dan Terapi Supportif Siswa SLB
}

\author{
Jainer Pasca Siampa ${ }^{1 *}$, Imam Jayanto ${ }^{1}$ \\ ${ }^{1}$ Program Studi Farmasi, Fakultas Matematika dan Ilmu Pengetahuan Alam, Universitas Sam Ratulangi \\ Manado, 95115, Sulawesi Utara, Indonesia \\ * Penulis korespondensi : Jainer Pasca Siampa, Program Studi Farmasi FMIPA Universitas Sam Ratulangi \\ Email : jainerpsiampa@unsrat.ac.id
}

\begin{abstract}
Abstrak
Berdasarkan hasil survei Badan Pusat Statistik (BPS), persentase tingkat pengangguran terbuka di Provinsi Sulawesi Utara meningkat dari 6,09 menjadi 6,86 di bulan Agustus 2018 atau setara dengan 80.664 orang. Kondisi serupa pun juga menjadi keluhan lulusan SLB di Sulawesi Utara. Menurut keterangan kepala sekolah SLB Khusus Autis Permata Hati dan YPAC Manado, lulusan SMA-LB sangat sulit untuk mendapatkan pekerjaan. Sehingga sangat penting dilakukan pembekalan kewirausahaan bagi anak didik. SLB Khusus Autis Permata Hati Manado dan SLB YPAC merupakan salah satu SLB yang fokus pada pendidikan anak autis dan anak dengan keterbatasan lainnya. Pembekalan kewirausahaan diharapkan dapat menjadi jawaban atas permasalahan keterbatasan kesempatan bekerja di kantor atau perusahaan sehingga dapat menghasilkan lulusan yang mandiri secara finansial. Fokus pada kegiatan ini adalah melatih guru-guru SLB Khusus Autis Permata Hati dan SLB Yayasan Pendidikan Anak Cacat (YPAC) Manado agar dapat membuat minuman kesehatan - Adanya kegiatan pelatihan pembuatan minuman kesehatan berbahan dasar jahe merah (Zingiber officinale) lokal Manado diharapkan dapat menjadi alternatif jenis usaha yang akan diajarkan dan dikembangkan di SLB ini sehingga alumninya nanti dapat berwirausaha. Minuman yang dihasilkan juga nanti dapat dikonsumsi sebagai minuman kesehatan yang baik bagi anak autis karena kandungan jahe merahnya. Kegiatan ini diharapkan akan bermuara pada alumni SLB yang hidup mandiri dengan membuka usaha shingga akhirnya dapat menurunkan tingkat pengangguran di Sulawesi Utara secara khusus. Hasil dari kegiatan ini adalah guru-guru telah memiliki pengetahuan baru tentang manfaat jahe merah untuk anak autis dan cara pembuatan minuman jahe instan sehingga akan menjadi bahan ajar pada mata pelajaran kewirausahaan pada kedua mitra SLB.
\end{abstract}

Kata kunci : pelatihan, produksi granul, jahe merah, SLB

\begin{abstract}
Based on the results of a survey by the Badan Pusat Statistik (Central Statistics Agency), the percentage of open unemployment in North Sulawesi Province increased from 6.09 to 6.86 in August 2018 or the equivalent of 80,664 people. Similar conditions are also a complaint of Sekolah Luar Biasa a.k.a SLB (Special Needs School) graduates in North Sulawesi. According to the headmaster of the Special SLB Autism Permata Hati and YPAC Manado, Senior high school graduates from SLB found difficulties to get a job. So it is very important to do entrepreneurship training for students. Permata Hati Manado Special School for Autism and SLB YPAC are special needs school that focus on the education of children with autism and children with other disabilities. Entrepreneurship provision is expected to be the answer to the problem of limited opportunities to work in offices or companies so that they can produce graduates who are financially independent. The focus of this activity is to train teachers of the SLB Permata Hati and SLB YPAC Manado to make healthy drinks. It is hoped that the training activities for making healthy drinks made from Manado local red ginger (Zingiber officinale) are expected to be an alternative type of business that will be taught and developed in this special needs school so that alumni can become entrepreneurs. The resulting drink
\end{abstract}


can also be consumed as a good health drink for autistic children because of its red ginger content. It is hoped that this activity will lead to SLB alumni who live independently by opening a business so that it can ultimately reduce the unemployment rate in North Sulawesi in particular. The result of this activity was that the teachers had new knowledge about the benefits of red ginger for children with autism and how to make instant ginger drinks so that it will become teaching materials in entrepreneurship subjects for both SLB partners.

Keywords: Workshop, granule production, red ginger, SLB

\section{PENDAHULUAN \\ Analisis Situasi}

Angka pengangguran terbuka merupakan gambaran persentase angkatan kerja yang mencari pekerjaan, mempersiapkan usaha, merasa tidak mampu mendapatkan pekerjaan, atau sudah mendapatkan pekerjaan tetapi belum mulai bekerja. Angka pengangguran terbuka di Sulawesi Utara pada Februari 2018 tercatat sebesar 6,09\%, lebih tinggi dari angka nasional sebesar $5,13 \%$. Angka ini kemudian meningkat pada bulan Agustus di tahun yang sama yaitu berada pada angka $6,86 \%$. Kepala BPS Sulut, dalam Harian Tribun Manado, 17 Mei 2018, mengatakan bahwa sebagian besar pengangguran merupakan pengangguran terdidik. Persentase tertinggi adalah pengangguran berpendidikan SMK dan selama setahun terakhir persentasenya meningkat secara signifikan sebesar 7,96\%. Data yang cukup ironi mengingat kurikulum SMK yang telah disusun agar dapat langsung bekerja atau berwirausaha setelah lulus. Hal ini juga selaras dengan kondisi lulusan SMA luar biasa yang memiliki keterbatasan dibandingkan dengan lulusan SMK biasa.

Sekolah Luar Biasa (SLB) merupakan sekolah yang menampung anak berkebutuhan khusus. Anak berkebutuhan khusus adalah anak yang mengalami keterbatasan atau keluarbiasaan, baik fisik, mental-intelektual, sosial, maupun emosional, yang berpengaruh secara signifikan dalam proses pertumbuhan atau perkembangannya dibandingkan anakanak lai yang seusia dengannya. Anak dengan gangguan spektrum autisma atau autism spectrum disorders (ASD) adalah anak yang mengalami gangguan dalam tiga area dengan tingkatan berbeda-beda, yaitu kemampuan komunikasi dan interaksi sosial, serta polapola perilaku yang repetitif dan stereotipi
(Kementerian Perberdayaan Perempuan dan Perlindungan Anak Republik Indonesia, 2013). Dari hasil wawancara singkat ini disimpulkan bahwa pada kegiatan Program Kemitraan Masyarakat (PKM) ini akan dilakukan pelatihan bagi guru-guru SLB untuk membuat suatu produk yang selanjutnya dapat menjadi produk wirausaha bagi alumni SLB. Minuman kesehatan dipilih karena sangat mudah dijumpai bahan baku, disukai oleh masyarakat, dan juga memiliki manfaat yang baik bagi siswa SLB secara khusus sehingga berpotensi sangat baik untuk dikembangkan. Pembuatan minuman ini berbahan dasar jahe merah lokal yang banyak dijumpai di kota Manado sehingga kontinuitas produksi nantinya dapat berjalan dengan lancar. Produk minuman kesehatan ini nantinya diharapkan dapat diajarkan dan menjadi produk inovasi karya siswa SLB yang dapat dikembangkan setelah lulus nantinya.

\section{Tujuan dan Manfaat Kegiatan}

Kegiatan pelatihan ini bertujuan untuk meningkatkan pemahaman dan keterampilan guru SLB Khusus Autis Permata Hati dan YPAC Manado tentang cara pembuatan minuman jahe merah instan. Manfaatnya adalah guru dapat mengajarkan kepada siswa SLB pada mata pelajaran Kewirausahaan sehingga lulusan SLB dapat mandiri secara ekonomi.

\section{METODE PELAKSANAAN \\ Sasaran Kegiatan Pengabdian}

Mitra pada kegiatan ini adalah seluruh guru pada SLB Khusus Autis Permata Hati dan YPAC Manado.

\section{Lokasi Kegiatan Pengabdian}

Kegiatan dilaksanakan pada SLB Khusus Autis Permata Hati dengan alamat Jalan Babe Palar No.25, Kecamatan Wenang, Kota Manado dan YPAC Manado dengan 
Jurnal Pengabdian Multidisiplin

alamat Jalan Raya Tanawangko, Kecamatan Malalayang, Kota Manado.

\section{Metode yang Digunakan}

Metode pelaksanaan kegiatan ini adalah:

1. Memberikan penyuluhan kepada mitra dengan topik bahasan antara lain:

- Peluang wirausaha bagi lulusan SLB

- Jahe merah, kandungan, dan manfaatnya

- Manfaat jahe merah untuk siswa autis

- Cara pemilihan bahan baku jahe merah dan pengolahan awalnya

- Komposisi minuman instan jahe merah

2. Memberikan pelatihan langsung tentang cara pembuatan, cara pengemasan dan memberi label produk, melihat slide show tentang tahapan pembuatan skala laboratorium, serta pelatihan tentang cara perhitungan harga jual.

3. Sesi tanya jawab tentang kondisi dan potensi kewirausahaan bagi siswa SLB.

\section{HASIL DAN PEMBAHASAN}

Kegiatan pengabdian ini telah dilaksanakan pada dua hari yang berbeda. Pada hari Selasa, 25 Agustus 2020 di SLB YPAC Manado dan dihadiri oleh 30 orang. Sedangkan di SLB Permata Hati dilaksanakan pada hari Kamis, 27 Agustus 2020 dan dihadiri oleh 20 orang. Peserta kegiatan terdiri dari guru SLB dan tim pengabdian (dosen dan mahasiswa).

Autisme adalah salah satu kelompok gangguan pada anak yang ditandai munculnya gangguan dan keterlambatan pada aspek kognitif, komunikasi, relasi sosial, dan perilaku (Hadis, 2006; Selvakumari et al., 2019). Gejala autisme biasanya dimulai pada usia 6 bulan ke atas dan kemudian berkembang hingga usia 2 tahun sampai usia dewasa. Terapi yang digunakan berdasarkan Complementary Alternative Medicine (CAM) dibagi menjadi 2 yaitu Secara biologis dan non biologis. Secara biologis termasuk didalamnya adalah intervensi diet. Yang paling populer dari terapi ini adalah diet bebas gluten dan latau casein. Selain itu dalam terapi biologis juga termasuk terapi nutrasetikal dan pemberian vitamin. Sedangkan pada terapi non biologis, berdasarkan The National Center for Complementary and Alternative Medicine (NCCAM) membagi dalam tiga kategori yaitu mind-body medicine (berdoa, yoga,, meditasi, musik, tarian, dan seni secara umum), manipulative and body-based practices (pijat, chiropractic care, dan akupuntur), dan energy medicine (Reiki atau Homeopaty) (Selvakumari, 2019). Pada terapi pengaturan pola makan termasuk didalamnya pemberian herbal.

Salah satu herbal yang dapat diberikan kepada penderita autis adalah jahe. Jahe (Zingiber officinale) merupakan rimpang yang sudah sangat familiar digunakan oleh masyarakat Indonesia sebagai bumbu dapur maupun sebagai bahan obat. Secara tradisional, rimpang jahe digunakan untuk mengobati batuk, sakit kepala, mual, dan permasalahan lain pada saluran pencernaan. Dalam pengobatan barat modern, rimpang jahe digunakan untuk pengobatan radang sendi, reumatik, ataupun ketidaknyamanan pada otot. Kandungan utama pada rimpang jahe adalah gingerol, shogaols, paradols, dan zingeron. Pengujian ekstrak jahe juga memperlihatkan aktivitas farmakologi yang luas antara lain sebagai analgetik, antibakteri, antialergi, antikonvulsan, immunomudulator, antifungi, antiinflamasi, neurotropik, antioksidan, dan masih banyak lagi. Jahe pun digunakan sebagai terapi pada penderita autis maupun gangguan perilaku lainnya (Hussein et al, 2018). Bagian tanaman jahe yang digunakan dan terbukti memberikan efek neuroprotektif pada penderita autis adalah bagian akar (rimpang) (Rezapour et al,2016).

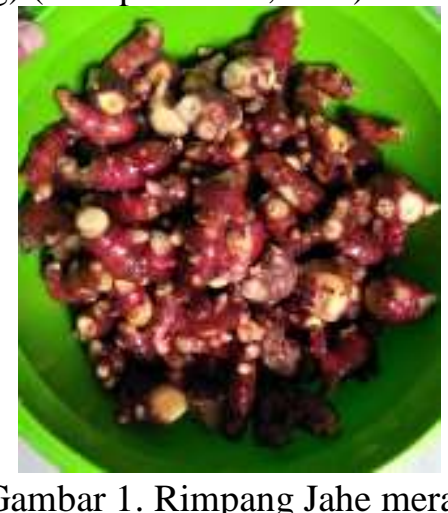

Dokumentasi Pribadi, 2020

Kegiatan pendidikan ini berisi tentang pemberian materi dan informasi mengenai peluang wirausaha bagi lulusan SLB, Jahe merah, kandungan, dan manfaatnya, manfaat jahe merah untuk siswa autis, cara pemilihan bahan baku jahe merah dan pengolahan awalnya, komposisi minuman instan jahe merah, cara pembuatan, cara pengemasan dan 
label produk minuman kesehatan, metode pembuatan dengan menggunakan peralatan rumah tangga, dan juga informasi mengenai manajemen pemasaran produk yang akan dijual.

Pembuatan granul jahe merah instan dilakukan dengan menggunakan metode granulasi basah (Lubis, dkk. 2016 ; Allen, 2014). Pertama-tama jahe merah dibersihkan dari kotoran dan bagian yang rusak. Kemudian dirajang tipis dan dikeringkan di oven dengan suhu $45^{\circ} \mathrm{C}$ selama 15 jam (Suhendra, 2017). Lalu kemudian setelah kering dihaluskan menggunakan blender. Kemudian selanjutnya dibuat granul. Lalu dilanjutkan dengan evaluasi. Evaluasi sediaan dilakukan berdasarkan Farmakope Indonesia meliputi uji organoleptik untuk melihat warna, rasa, dan aroma. Uji waktu alir, sudut kontak, dan kadar air untuk mengetahui kualitas granul. Setelah semua proses pengujian memenuhi syarat, selanjutnya dilakukan pengemasan dan diberikan label produk (Rowe et al, 2009).

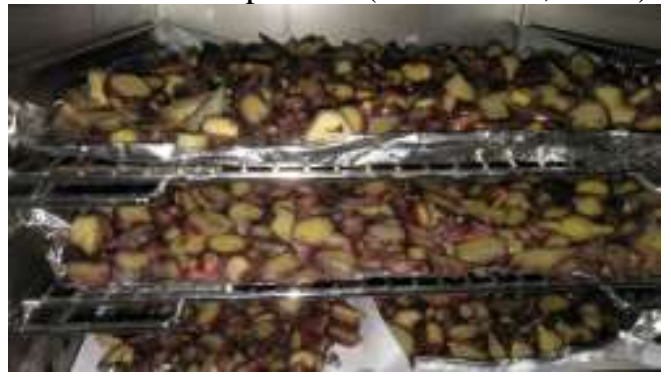

Gambar 2. Proses Pengeringan Jahe Merah Menggunakan Oven

Jahe merah dirajang melintang untuk mempertahankan kandungan minyak atsirinya. Pengeringan yang dilakukan dengan menggunakan oven menghasilkan jahe kering dengan cepat sehingga kandungan minyak atsiri dan fenolnya bisa lebih banyak (Almasyhuri et al., 2012).

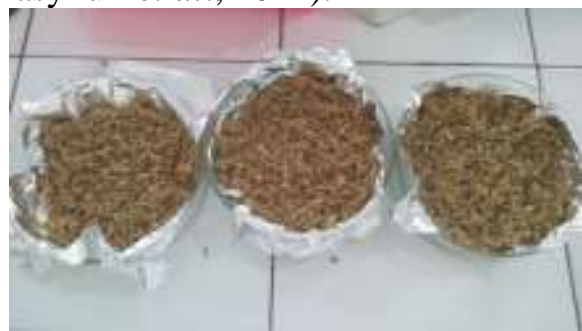

Gambar 3. Jahe merah yang sudah diblender kasar

Oleh karena keterbatasan waktu pertemuan selama pandemi, maka kami melakukan modifikasi pada saat pelaksanaan kegiatan pelatihan yaitu dengan cara jahe merah sudah diproses di laboratorium terlebih dahulu mulai dari pembersihan, perajangan, pengeringan dan pembuatan granul. Tahapan ini dijelaskan sambil melihat slide show dokumentasi pelaksanaannya. Setelah itu, dilakukan proses pengemasan dan pelabelan produk bersama dengan mitra.

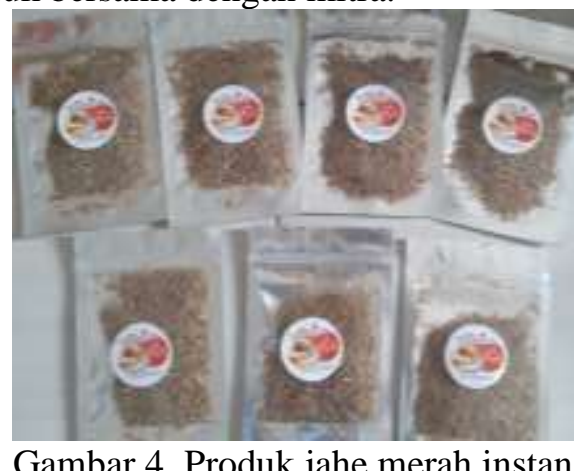

Gambar 4. Produk jahe merah instan

Pada saat pelaksanaan, dijelaskan pula bahwa proses pengeringan jahe bisa menggunakan metode konvensional yaitu dengan menjemur dibawah sinar matahari selama 2 hari ataupun diangin-anginkan selama 7 hari (Almasyhuri et al., 2012). Hal ini akan memudahkan mitra untuk melakukan kegiatan produksi dengan peralatan rumah tangga. Namun, perlu dilakukan perajangan terlebih dahulu agar jahe bisa kering dengan baik.
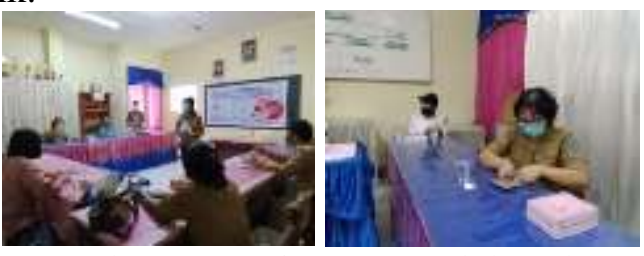

Gambar 5 . Kegiatan Penyuluhan dan pelatihan

Selain itu dilakukan pelatihan langsung tentang cara penetuan harga jual produk. Dilakukan pelatihan mulai dari perhitungan biaya tetap, biaya variabel, harga jual per unit, dan penentuan BEP (break even point). Para mitra berlatih melakukan perhitungan harga jual dengan beberapa metode antara lain Metode Keystone Pricing, MSRP (Manufacturer Suggested Retail Price), Mark Up, Paketan / Grosir, Cost-plus Pricing, Value Based Pricing (VBP) (Setiadi, 2014; Slat, 2013; Samsul, 2013; Djumali, 2014; Panomban, 2013).

Dalam kegiatan ini, mitra sangat antusias menerima materi dan melakukan 


\section{Kesimpulan}

interaksi pada sesi tanya jawab mengenai proses produksi, cara mendapatkan kemasan dan label, serta penentuan harga jual. Keberhasilan kegiatan dinilai saat penyelesaian soal post test mengenai tahapan pembuatan dan perhitungan harga jual secara berkelompok oleh mitra. Mitra dapat menjawab semua pertanyaan dengan benar.
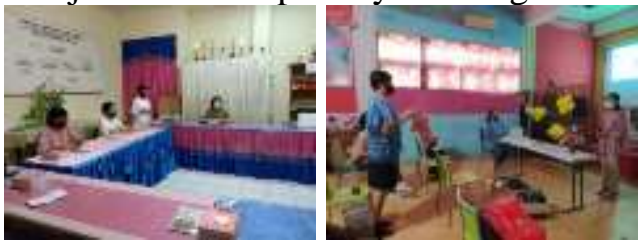

Gambar 6. Sesi tanya jawab

Di masa pandemi Covid-19 ini, kegiatan juga dirangkaikan dengan pemberian sembako kepada para peserta kegiatan untuk mendukung ketahanan pangan para guru.
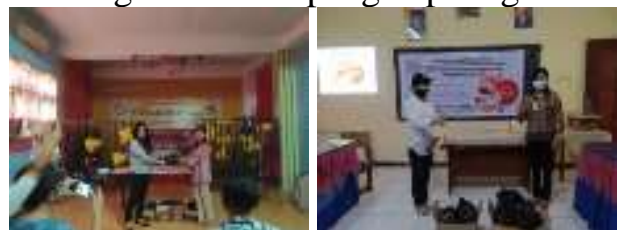

Gambar 7. Penyerahan sembako untuk mitra

Setelah kegiatan selesai, dilakukan sesi foto bersama dengan peserta kegiatan PKM.

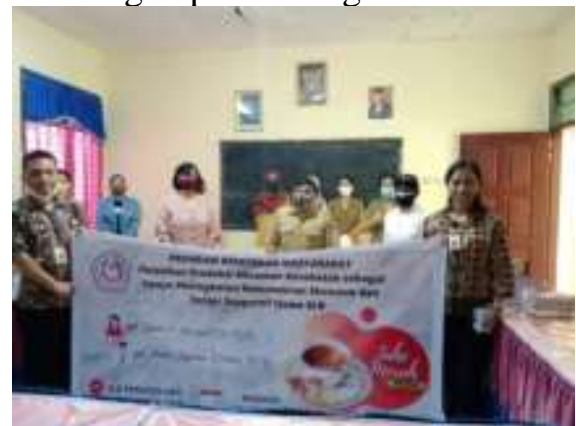

Gambar 8. Pelaksanaan kegiatan PKM di SLB YPAC Manado

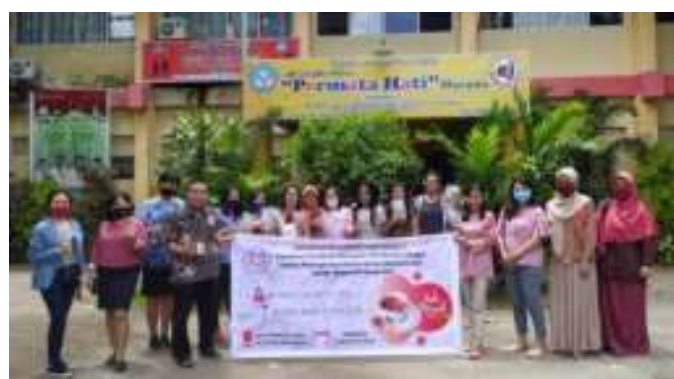

Gambar 9. Pelaksanaan kegiatan PKM di SLB Permata Hati

\section{KESIMPULAN DAN SARAN}

1. Pelatihan produksi minuman kesehatan granul jahe merah instan menambah wawasan dan keterampilan guru SLB YPAC Manado dan SLB Permata Hati.

2. Materi pelatihan dapat menjadi bahan ajar dalam mata pelajaran Kewirausahaan sehingga siswa SLB dapat mempunyai bekal untuk berwirausaha dan mandiri secara ekonomi.

3. SLB dapat memproduksi minuman kesehatan sebagai terapi supportif pada peserta didik SLB.

\section{Saran}

Kegiatan penyuluhan tentang produksi minuman kesehatan berbahan dasar herbal asli daerah Manado yang lain dapat dilakukan sehingga bisa dikembangkan untuk menjadi produk ciri khas SLB.

\section{UCAPAN TERIMAKASIH}

Terimakasih kepada Kementerian Pendidikan dan Kebudayaan melalui Lembaga Penelitian dan Pengabdian Masyarakat Universitas Sam Ratulangi (LPPM- Unsrat) yang telah membiayai kegiatan Program Kemitraan Masyarakat tahun pendanaan 2020 dengan Surat Tugas No. 1126/UN12.13/PMPNBP/2020.

Terima kasih kepada kedua mitra yaitu SLB YPAC Manado dan SLB Permata Hati yang telah berkenan menerima tim PKM.

\section{DAFTAR PUSTAKA}

Hussain, Sajid dan Maheshwary, K.K. 2018. Pharmacological Screening of Extract of Zingiber officinale in Socially Deficit Rats by Three-Chambered Social Test. World Journal of Pharmaceutical Research Volume 7, Issue 1, 898-912.

Allen LV dan Ansel HC. 2014. Ansel's Pharmaceutical Dosage Forms and Drug Delivery System Tenth Edition. USA

Suhendra L, 2017. Efektifitas Pengeringan Jahe (Zingiber officinale Roscoe) Terhadap Aktivitas Antioksidan. Fakultas Teknologi Industri Fakultas Teknologi Pertanian Udayana 
Hadis A. 2006. Pendidikan Anak Berkebutuhan Khusus-Autistik. Bandung: Alfabeta

Kementerian Pemberdayaan Perempuan dan Perlindungan Anak Republik Indonesia. 2013. Panduan Penanganan Anak Berkebutuhan Khusus Bagi Pendamping (Orang tua, Keluarga, dan Masyarakat). Jakarta

Lubis N, Prasetiawati R, Rahmat G. 2016. Formulasi, Evaluasi, dan Perbandingan Intensitas Kepedasan Granul Effervescent Jahe. IJPST Volume 3 Nomor 1

Rowe RC, Sheskey PJ, Quinn ME. 2009. Handbook of Pharmaceutical Excipients Sixth Edition. USA

Website resmi badan Pusat Statistik http://bps.go.id

Selvakumari, V, R. Senthamarai, T. Shri Vijaya Kirubha, P. Balasubramanian, V.Kavitha. 2019. Herbal Beneficiaries in Autism Spectrum Disorder. International Journal of Research in Pharmacology \& Pharmacotherapeutics. Volume 8 Issue 3 pp 404-408

Rezapour, Sadegh, Bahmani M, Afsordeh O, Rafieian R, Sheikhian A. 2016. Herbal Medicine: A New Hope For Autism Therapy. Journal of Herbmed Pharmacology. Volume 5 Issue 3 pp8991.

Almasyhuri, Wardatun S, Nuraeni L. 2012. Perbedaan Cara Pengirisan dan Pengeringan Terhadap Kandungan Minyak Atsiri Dalam Jahe Merah (Zingiber officinale Roscoe .Sunti Valeton). Available at digilib.mercubuana.ac.id.

Slat, AH, 2013. Analisis Harga Produk Dengan Metode Full Costing dan Penentuan Harga Jual, Jurnal EMBA, 1(3): $110-117$

Samsul, NH, 2013. Perbandingan Harga Pokok Produksi Full Costing dan Variable
Costing Untuk Harga Jual CV. Pyramid, Jurnal EMBA, 1(3): 366-373

Setiadi, P, Saerang DPE, Runtu T, 2014. Perhitungan Harga Pokok Produksi Dalam Penentuan Harga Jual Pada CV. Minahasa Mantap Perkasa, Jurnal Berkala Ilmiah Efisiensi, 14(2): 70-81

Djumali, I, Sondakh, JJ, Mawikere, L, 2104. Perhitungan Harga Pokok Produksi Menggunakan Metode Variable Costing Dalam Proses Penentuan Harga Jual Pada PT. Sari Malalugis Bitung, Jurnal Berkala Ilmiah Efisiensi, 14(2): 82-91

Ponomban, CP, 2013. Analisis Break Even Point Sebagai Alat Perencanaan Laba Pada PT. Tropica Cocoprima, Jurnal EMBA, 1(4): 1250-1261 